\title{
Sicherung von Schmerzensgeldansprüchen nach terroristischen Anschlägen durch Pfändung von ausgestellten Kunstgegenständen?
}

\author{
Landgericht Berlin, Beschluss vom 4. Februar 2010 - 130 48/10
}

\section{1. §882 a Abs. 2 ZPO ist auf die Pfändung von Kunstgegenständen eines ausländischen Staates, die sich während einer Ausstellung im Inland befinden, analog anzuwenden.}

2. Gegenüber der auch an Privatpersonen gerichteten Bestimmung des $\$ 20$ Kulturgut-Abwanderungsschutzgesetz verfolgt § 882 a ZPO den Zweck, solche Gegenstände juristischer Personen zu schützen, deren Veräußerung ein öffentliches Interesse entgegensteht. (Leitsätze der Redaktion)

\section{Tenor}

I. Der Antrag des Antragstellers vom 3. Februar 2010 auf Erlass des dinglichen Arrestes wird zurückgewiesen.

II. Die Kosten des Verfahrens hat der Antragsteller zu tragen.

III. Der Streitwert wird auf 5.000,00 Euro festgesetzt.

\section{Gründe}

- Der Antragsteller ist Opfer des terroristischen Anschlags vom 25. August 1983 auf das seinerzeitige französische Kulturzentrum Maison de France in Berlin-Charlottenburg und beantragt, einen Schmerzensgeldanspruch gegen die Antragsgegnerin durch einen Arrest zu sichern, der durch Pfändung zweier in Stuttgart ausgestellter Kunstgegenstände vollzogen werden soll.

Dieser Antrag war zurückzuweisen, da weder ein durchsetzbarer Arrestanspruch noch Arrestgrund gegeben sind, §§ 916 ff. ZPO.

Es besteht kein durchsetzbarer Arrestanspruch, da ein möglicher Anspruch des Antragstellers zumindest verjährt wäre und davon auszugehen ist, dass die Antragsgegnerin die Einrede bei Gewährung rechtlichen Gehörs auch erheben würde.

Der Antragsteller stützt sich auf einen Anspruch auf Schmerzensgeld aus § 823 BGB iVm Völker(gewohnheits)recht, für den bereits zum Zeitpunkt des Entstehens im Jahre 1983 die dreijährige Verjährungsfrist des § 852 BGB (a.F.) galt. Hiernach verjährt der Anspruch „in drei Jahren von dem Zeitpunkt an, in welchem der Verletzte von dem Schaden und der Person des Ersatzpflichtigen Kenntnis erlangt". Vorliegend hat der Antragsteller spätestens mit dem Urteil des Landgerichts Berlin vom 17. Januar 2000, Anlage K 2b, über das auch in den Medien berichtet wurde, von der Beteiligung der Antragsgegnerin an dem schadensursächlichen Anschlag Kenntnis erlangt und hätte seinen Schmerzensgeldanspruch daher auch klageweise geltend machen können. Anders als die heutige Regelung des $\S 199$ Abs. 1 BGB stellte die Vorschrift des § 852 BGB für den Beginn der Verjährungsfrist nicht auf das Ende des Jahres, in dem Kenntnis erlangt wurde, sondern auf den konkreten Zeitpunkt der Kenntniserlangung ab. Demnach wäre die Verjährungsfrist nach der Schuldrechtsreform des Jahres 2002 länger gewesen als zuvor, so dass Art. $229 \S 6$ Abs. 3 EGBGB zur Anwendung kommt, der bestimmt, dass dann die alte Verjährung gilt. Auf die Frage, ob die erstmals mit Schreiben des Antragstellers vom 1. März 2004, also nach Vollendung der Verjährung, gegenüber der Antragsgegnerin vorgenommene Geltendmachung der Ansprüche zu verjährungshemmenden Verhandlungen führte, kommt es demgemäß nicht an. Allerdings wäre eine solche Annahme schon unter dem Gesichtspunkt problematisch, dass der Antragsteller ausdrücklich nur um eine Prüfung einer eine Anerkennung des Anspruchs nicht voraussetzenden Entschädigung „ex gratia“ gebeten hat, und nur darüber wurde überhaupt verhandelt.

Zudem besteht kein Arrestgrund, denn der Antragsteller hat nicht ausreichend glaubhaft gemacht, dass der Antragsgegnerin keine Vermögenswerte in Deutschland oder im europäischen Ausland gehören, die für eine Urteilsvollstreckung zur Verfügung stehen.

Gegen den Erlass des beantragten Arrestes spricht zudem, dass die vom Antragsteller benannten Kunstgegenstände dem Pfändungsschutz entsprechend § 882 a Abs. 2 ZPO unterfallen und deshalb die in Aussicht genommene Vollziehung ausgeschlossen ist.

Dem Urteil des Kammergerichts vom 26. Juni 2002 (Az. 9 W 176/02) folgend, ist $\S 882$ a Abs. 2 ZPO auf die Pfändung von Kunstgegenständen eines ausländischen Staates, die sich während einer Ausstellung im Inland befinden, analog anzuwenden. Dem kann nicht entgegengehalten werden, der Gesetzgeber habe durch die Einführung des $§ 20$ KulturgutAbwanderungsschutzgesetz eine entsprechende Lücke im Vollstreckungsschutz in Bezug auf ausländische Kulturgüter schließen wollen, so dass diese Vorschrift als abschließend zu verstehen sei. Zwar sieht die Vorschrift in ihrem Abs. 4 die Unzulässigkeit unter anderem auch von Arrestverfügungen für die Dauer der Gewährung "freien Geleits" für Kulturgüter vor, jedoch richtet sie sich auch an Privatpersonen, denen auf diesem Wege die Zurückerlangung des für eine Ausstellung zur Verfügung gestellten Kulturguts rechtsverbindlich zugesichert werden soll. Demgegenüber verfolgt § 882 a ZPO den Zweck, solche Gegenstände juristischer Personen zu schützen, deren Veräußerung ein öffentliches Interesse entgegensteht, 
und sichert hiermit die Entscheidung des Schuldners darüber, ob derartiges Staatseigentum verwertet werden kann, ohne dass hierfür die Gewährung „freien Geleits" im Sinne des § 20 Kulturgut-Abwanderungsschutzgesetz erforderlich ist. Die entsprechende Anwendung des $\S 882$ a Abs. 2 ZPO ist auch geboten, da es sich vorliegend um zum nationalen Kulturgut des betroffenen Staates gehörende Kunstgegenstände handelt.
Die Kostenentscheidung beruht auf § 91 Abs. 1 ZPO.

Die Streitwertfestsetzung richtet sich nach $\S 53$ Abs. 1 Nr. 1 GKG iVm § 3 ZPO. (Entscheidung von der Redaktion bearbeitet.)

\title{
Kunsthandwerk und künstlerische Tätigkeit - Zur Definition des Kunstbe- griffs im Sinne des Künstlersozialversicherungsgesetzes (KSVG)
}

\author{
Sozialgericht Bremen, Urteil vom 25. März 2010 - S 4 KR 77/07
}

\section{Bei der Herstellung von Ausschneidebogen für den Bau mechanischer Skulpturen aus Papier handelt es sich um eine künstlerische Tätigkeit iSd Künstlersozialversicherungsgesetzes (KSVG). Da die Ausschneidebogen das Ergebnis einer eigenschöpferischen Leistung sind, bei dem der Schwerpunkt auf der Idee der zu erzählenden Ge- schichte sowie der gestalterischen Umsetzung liegt, handelt es sich nicht um eine Form von (Kunst-) Handwerk. 2. Trotz der handwerklichen Arbeit ist eine Zuordnung zum Bereich der Kunst im Übrigen dann möglich, wenn der handwerklich tätige Künstler mit seinen Werken in Kunstkreisen als Künstler anerkannt und behandelt wird. 3. Die Möglichkeit, eine Idee theoretisch unbegrenzt zu reproduzieren, schließt Kunst nicht aus. (Leitsätze der Redaktion)}

\section{Tenor}

Unter Aufhebung des Bescheides der Beklagten vom 28. August 2006 und des Widerspruchsbescheides vom 11. Mai 2007 wird festgestellt, dass der Kläger seit dem 1. Januar 2007 der Versicherungspflicht nach dem Künstlersozialversicherungsgesetz unterliegt. Im Übrigen wird die Klage abgewiesen. Die außergerichtlichen Kosten des Klägers hat die Beklagte zu erstatten.

\section{Tatbestand}

- Streitig ist die Versicherungspflicht des Klägers nach dem Künstlersozialversicherungsgesetz (KSVG).

Der 1949 geborene Kläger ist ausgebildeter Lehrer mit beiden Staatsexamina. Bis Ende März 2004 arbeitete er insgesamt ca. 25 Jahre in der beruflichen Weiterbildung. Bereits Ende November 2000 meldete der Kläger daneben ein Gewerbe für die Herstellung und den Verkauf von Skulpturen sowie die Herstellung und den Verkauf von mechanischen Modellen an. Nach der Kündigung durch seinen Arbeitgeber bezog der Kläger im Zeitraum 1. April 2004 bis 25. Mai 2006 Arbeitslosengeld I. Ausweislich des Einkommenssteuerbescheides 2006 erzielte er im Kalenderjahr 2006 1.247,00 Euro an Einkünften aus Gewerbebetrieb.

Am 17. Mai 2006 stellte der Kläger bei der Beklagten den Antrag auf Feststellung der Versicherungspflicht. Er sei nach Auslaufen seines Arbeitslosengeldes von nun [an] als Maler, Zeichner, künstlerischer Grafiker, Bildhauer sowie mit ähnlicher künstlerischer Tätigkeit im Bereich bildender Kunst hauptberuflich selbstständig tätig. Die von ihm entwickelten und aus
Papier bestehenden mechanischen Modelle verkaufe er als Ausschneidebogen über das Internet weltweit sowie über lokale Geschäftspartner und Zwischenhändler. Die Bausätze seien teilweise auch in Fachgeschäften und Museumsshops erhältlich. Daneben fertige er insbesondere für Museen Einzelstücke und Großskulpturen als Auftragsarbeit, organisiere Ausstellungen durch seine Papiermechanik-Sammlung, führe Papiermechanik-Workshops als VHS-Kurse und im Rahmen der Lehrerfortbildung durch und habe im Jahr 2003 ein englischsprachiges Handbuch über Papiermaschinen veröffentlicht sowie mehrere Fachartikel verfasst.

Auf die Bitte der Beklagten im Verwaltungsverfahren, Nachweise über die Anerkennung als Künstler in entsprechenden Fachkreisen bildender Künstler vorzulegen, teilte der Kläger mit, der Anerkennungsnachweis sei schwierig zu erbringen. Sein Hauptprodukt "Ausschneidebogen für den Bau mechanischer Skulpturen" sei in der deutschen akademischen Kunstszene weitgehend unbekannt. International sei dies anders. Dort sei er als Künstler anerkannt.

Mit Bescheid vom 28. August 2006 lehnte die Beklagte die Feststellung der Versicherungspflicht nach dem KSVG ab. Bei der Tätigkeit des Klägers handele es sich um Kunsthandwerk. Der Kläger fertige Skulpturen aus Pappe an. Um eine künstlerische Tätigkeit handele es sich nur dann, wenn eine entsprechende Anerkennung in einschlägigen fachkundigen Kreisen als Künstler anerkannt sei. Dafür sei hier nichts ersichtlich.

Gegen den ablehnenden Bescheid der Beklagten legte der Kläger mit Schreiben vom 13. September 2006 Widerspruch ein. Es handele sich nicht um eine handwerkliche, sondern um eine 